Document downloaded from:

http://hdl.handle.net/10251/102177

This paper must be cited as:

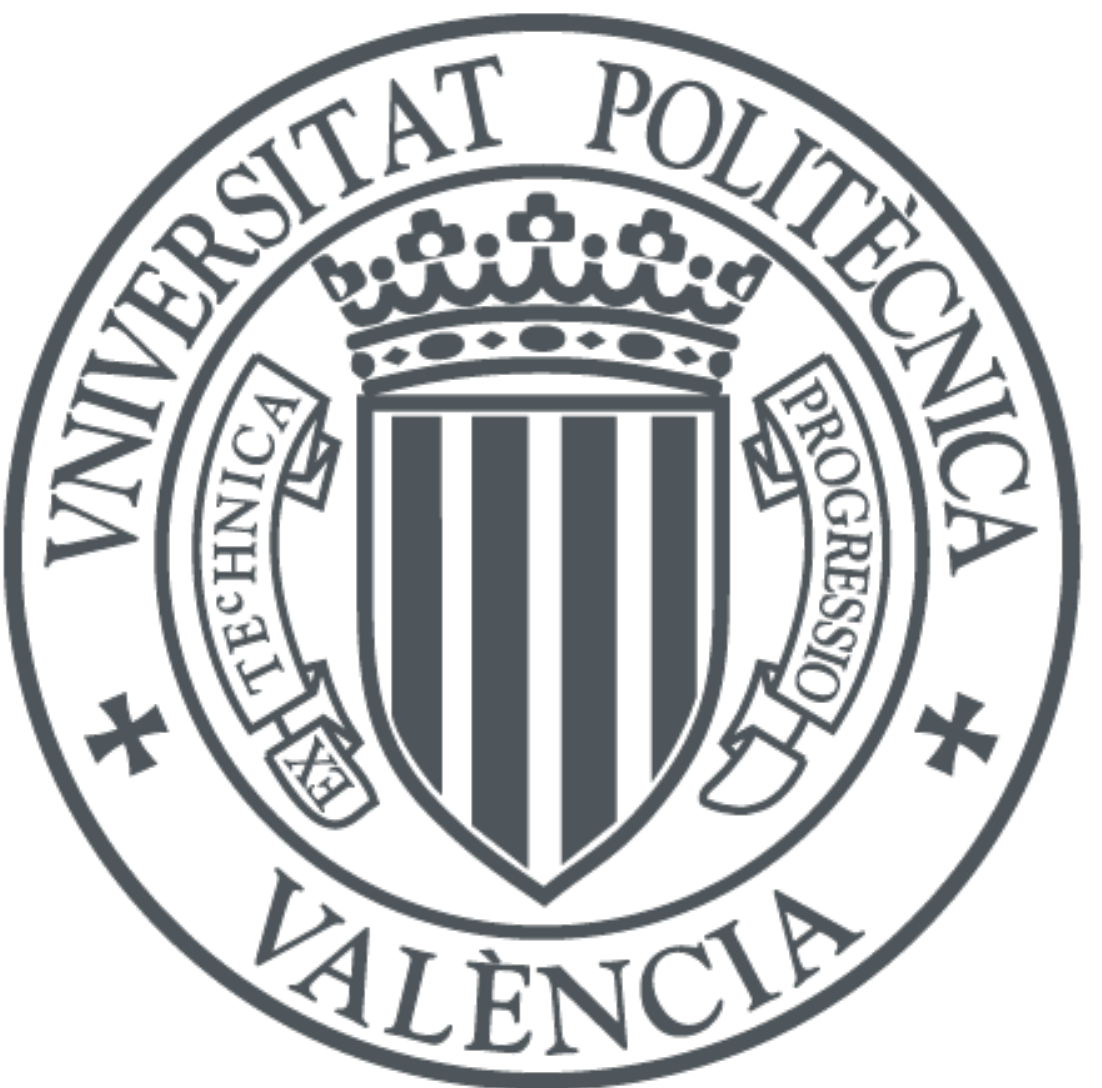

The final publication is available at

https://doi.org/10.1177/1468087416679569

Copyright SAGE Publications

Additional Information 


\title{
Analysis of the role of altitude on Diesel engine performance and emissions using an atmosphere simulator
}

\author{
Vicente Bermúdez¹, José Ramón Serrano', Pedro Piqueras', Javier Gómez¹ and Stefan \\ Bender $^{2}$
}

\begin{abstract}
Forthcoming directives from European Commission will force homologation in altitude to approach standards to actual driving conditions in order to reduce the gap between regulated and real-life emissions. This work presents the use of a dedicated atmosphere simulator to analyse the impact of altitude on performance and emissions of a turbocharged Diesel engine. The presented equipment provides engine intake and exhaust pressure to reproduce high altitude conditions. Main advantages are related to cost savings with respect to round-robin testing campaigns ensuring controlled ambient conditions at the different altitudes. The paper shows the main features of the altitude simulator under steady-state and transient operation and the ability to control temperature at the same time that pressure according to ISA specifications. The experimental results highlight the need of specific testing facilities to perform calibration tasks as key tool to comply with future emission standards in a cost-effective manner. In particular, regulated emissions measured at altitude are shown to clearly exceed that permitted at sea-level emphasising the need to explore new dedicated engine control strategies for pollutant abatement under altitude operation.
\end{abstract}

\section{Keywords}

Internal combustion engine, standards, altitude, emissions, performance

\section{Introduction}

Upcoming regulations as World-wide harmonized Light vehicles Test Cycle (WLTC) (1), which will include altitude and cold tests, will force to optimise engine performance and emissions under these operating conditions. For that reason, it is important to have available useful experimental tools able to carry out tests in such low pressure and low temperature operating conditions. For example, Sierra Nevada in Granada (Spain) has roads over $2500 \mathrm{~m}$ with noticeable temperature variations ranging from $0{ }^{\circ} \mathrm{C}$ to $35^{\circ} \mathrm{C}$ during the year.

The reduction of ambient pressure with altitude reduces also the air density (2), what highly affects the engine response. For example, the decrease of the in-cylinder density causes smaller drop size, which leads to coalescence reduction (3; 4). This lower coalescence would decrease jetto-wall impingement, but the lower density also decreases the spray angle thus leading to increase the spray penetration (5). In parallel, the combustion start is advanced as altitude increases producing higher maximum in-cylinder pressure which results in the increase of mechanical loads on the cylinder walls (6). Other effect of the lower density is the increase of the lift-off, which increases the fresh air penetration in the jet decreasing initial soot formation $(7 ; 8)$.

\footnotetext{
${ }^{1}$ Universitat Politènica de València, CMT-Motores Térmicos, Spain ${ }^{2}$ HORIBA Europe Gmbh, Germany

Corresponding author:

Pedro Piqueras, Universitat Politènica de València, CMT-Motores Térmicos, Camino de Vera s/n, 46022, Valencia, Spain

Email: pedpicab@mot.upv.es
} 
However, the lower oxidation rate of the soot caused by the lower density in the combustion chamber globally increases soot formation at the end of the combustion process.

These examples show how many factors are affected by the altitude at which the engine works. Hence, the diversity of published studies analysing the altitude influence on engine performance and emissions. Some of them are based on the use of computational tools; for example Zhu et al. (9) optimized injection parameters using a Genetic Neuronal Network in order to improve engine performance but without taking into account emissions. Other researchers focused on real driving emissions at different plateau altitudes; for example, in the work of Wang et al. (10) a vehicle powered by a $2.8 \mathrm{l}$ turbocharged diesel engine was driven at altitudes of 1000, 2400 and $3200 \mathrm{~m}$ and at constant vehicle speeds ranging from $10-90 \mathrm{~km} / \mathrm{h}$ in order to analyse regulated emissions. It was observed that $\mathrm{CO}, \mathrm{HC}$ and $\mathrm{PM}$ emissions increased with altitude. However, NOx emission also increased up to $2400 \mathrm{~m}$ but a decrease was found at $3200 \mathrm{~m}$. However, these conclusions are only based on 10 steady-state operating points focusing on the influence of engine speed and relying on intake charge variation because of density decrease as altitude increases to explain emissions variation.

Other group of studies on altitude influence are performed in altimetric tests benches (11). The tests are performed by simulating altitude conditions in the test cell environment, what involves large volume because of the need of high mass flow renewal without pressure and temperature variations. It contrast with the proposed equipment in this work, which is based on a mobile solution able to be shared by conventional engine test cells and ensuring fast dynamic response to engine requirements in a compact packaging.

Concerning the improvements of the engine response, some techniques have been proposed to solve altitude penalty on performance. Due to the fact that at low ambient pressure the intake air mass flow decreases, some studies are driven to analyse the potential of enriched oxygen fuel (12) as a way to improve the engine performance. NOx emissions have been discussed not to be directly affected by fuel oxygen (13), so that can be proposed as potential improvement. Another solution is based on two-stage sequential turbocharging system to increase maximum available pressure ratio so that boosting pressure at sea-level conditions can be kept at high altitude (14). This kind of boosting architecture was shown to allow reaching the same engine power output that at sea-level up to $2000 \mathrm{~m}$ recovering up to $80 \%$ at $5500 \mathrm{~m}$. However it involves oversize the boosting system for sea-level operation increasing the engine cost and size. In addition concerns on turbocharger maximum temperature, surge margin and engine emissions should be addressed.

In this paper, the operating principle of a mobile altitude simulator $(15 ; 16 ; 17)$ is presented. The first part of the paper is focused on the description of the equipment layout, operation maps and performance in terms of pressure, temperature and mass flow conditioning. This equipment allows keeping constant pressure and temperature in the engine intake and exhaust with high dynamic response against demanded fresh air mass flow variation. Its main advantages are referred to control of ambient conditions thus providing high test repeatability conditions with significant cost-savings related to calibration test campaigns in comparison to other available solutions. In the second part of the work the altitude simulator is used to obtain a complete engine mapping at different altitudes. Driving cycles has been also performed to demonstrate the dynamic response of the equipment. Combination of steady-state and transient operation tests provides a comprehensive range for engine performance and emissions analysis. The obtained results evidence the need to include altitude as a key parameter to effectively reduce exhaust gases emissions under real driving conditions in future generation of internal combustion engines.

\section{Altitude simulator}

An altitude simulator called HORIBA MEDAS (Mobile Efficient and Dynamic Altitude Simulator) has been developed to assess engine response operating in different ambient conditions imposed by height. The operating principle of this altitude simulator is explained in detail in (17). Some of its design features and performance were already discussed in works related to a previous version of MEDAS (18).

The installation can work in two different operation modes just by changing the position of a series of valves (17): 
- Vacuum mode, when the pressure ratio between simulated and actual altitudes is lower than one, i.e. simulated altitude is over engine location one.

- Over-pressure mode, when the pressure ratio between simulated and actual altitudes is higher than one, i.e. simulated altitude is below engine location one.

Figure 1 shows MEDAS configured in vacuum operation mode, which is the one applied in the engine testing campaign analysed in this work. The valves plotted in black color means that are fully closed while white background means open valve. The working pressure, temperature and mass flow across MEDAS are set by the mechanical compressor speed (element (17) in Figure 1), the VGT position (8) and the position of two control valves socalled VGT (5a) and WG (6) valves respectively. Fresh air in ambient conditions enters the systems across filter (2) and is driven to VGT (8) and WG (6) branches because valve (5b) is kept closed. The air mass flow through the VGT is expanded and cooled down from ambient conditions to the pressure of the altitude that is being simulated. The VGT power is dissipated in an independent turbocompressor (9). Alternatively, the WG valve position can be managed in parallel. Basically, it allows increasing the air mass flow and pressure for a given VGT opening and mechanical compressor (17) speed but keeping ambient flow temperature. An intermediate temperature is obtained at engine intake when both flows join downstream of the VGT and WG branches. The combination of the VGT and WG settings together with the mechanical compressor speed allows controlling pressure and air mass flow but also provides a good margin for temperature control, as forward explained in next section.

A cyclonic separator (13) is installed downstream of the VGT to separate the ice or water generated because of very low temperature. Then, part of the air mass flow is aspirated by the engine intake (1a). The equipment works always with excess mass flow, which is by-passed to pipe (3b) and diluted with exhaust gas mass flow coming from the engine (3a). This by-pass pipe (4) ensures engine operation with equal intake and exhaust pressure.

Due to the fact that valve (23) is closed and valve (15) is open, the mixture of dilution air and exhaust gases is driven to a cooler (14) placed upstream of the mechanical compressor (17). The cooler function is to ensure safe operation of the compressor in terms of inlet and outlet temperature. In turn it additionally reduces the compressor power consumption. To avoid the effects of condensates formed when the exhaust gas is cooled down, which might damage compressor blades (19), another cyclonic separator (16) is installed between the cooler and the mechanical compressor. The risk of condensates and its generation rate is mainly depending on the engine equivalence ratio, gas pressure, installation dilution ratio and cooler outlet temperature. The mechanical compressor speed is controlled by means of the speed of an electric motor (18) coupled to a variable-frequency drive. Finally, control on valves (19a) and (19b) allows discharging the exhaust gases to the atmosphere (20).

\section{MEDAS operating range}

Figures 2 and 3 show MEDAS operating maps concerning mass flow and temperature variation with respect to room conditions in vacuum and overpressure operating modes. Vacuum mode range is referred to MEDAS placed at sealevel simulating pressure at any higher altitude up to $7000 \mathrm{~m}$; over-pressure mode range is referred to MEDAS placed at any altitude up to $3000 \mathrm{~m}$ simulating lower altitudes.

In Figure 2, the $\mathrm{x}$-axis at the top of the plot represents the pressure at the engine intake (pipe (1a) in Figure 1) and the $\mathrm{x}$-axis at the bottom represents the corresponding altitude according to ISA. The y-axis represents the air mass flow entering to the installation. MEDAS can reproduce sea-level for a test bench located up to $3000 \mathrm{~m}$ and emulate altitudes from sea-level up to $7000 \mathrm{~m}$. As examples, at $5000 \mathrm{~m}$, which corresponds to a pressure of 0.54 bar, the maximum air mass flow that can be streamed up by MEDAS is around $720 \mathrm{~kg} / \mathrm{h}$ whilst a test bench placed at $2000 \mathrm{~m}$ in height can reproduce sea-level pressure providing a maximum air mass flow of $1200 \mathrm{~kg} / \mathrm{h}$.

Figure 3 shows the temperature variation of the fresh air mass flow in vacuum mode and over-pressure mode as a function of the simulated altitude. As example, the air temperature can be cooled down up to $22{ }^{\circ} \mathrm{C}$ below room temperature at $5000 \mathrm{~m}$ in vacuum mode. The installation ensures regulation capability within this boundary and room temperature. Similarly, the minimum air temperature is 
close to cooling water temperature in over-pressure mode simulating sea-level pressure whatever the altitude at which is placed the installation. Under this operating mode, the maximum air temperature is defined by the mechanical compressor outlet temperature.

\section{Engine characteristics}

The engine described in Table 1 was coupled to MEDAS as shown in Figure 4. The engine intake was connected to pipe (1a) and the engine exhaust to pipe (3a) according to numbering in Figure 1. The engine sump was also connected to pipe (4b) to provide the same vacuum pressure to the sump than to the intake and exhaust of the engine.

Table 1. Specifications of the tested Diesel passenger car engine.

\begin{tabular}{ll}
\hline \hline Type & HSDI - Euro 4 \\
Displacement & $1997 \mathrm{~cm}^{3}$ \\
Diameter & $85 \mathrm{~mm}$ \\
Stroke & $88 \mathrm{~mm}$ \\
Number of cylinders & $4 \mathrm{in} \mathrm{line}$ \\
Valves & 4 per cylinder \\
Compression ratio & $15.5: 1$ \\
Maximum power & $120 \mathrm{~kW}$ at $3750 \mathrm{rpm}$ \\
Maximum torque & $340 \mathrm{Nm}$ at $2000 \mathrm{rpm}$ \\
Maximum mass flow & $640 \mathrm{~kg} / \mathrm{h}$ at $4500 \mathrm{rpm}$ \& full-load \\
Turbocharger & Single-stage VGT \\
EGR type & Cooler, short-route with intake throttle \\
\hline \hline
\end{tabular}

A complete engine mapping covering different altitudes $(150 \mathrm{~m}, 1000 \mathrm{~m}, 2000 \mathrm{~m}$ and $3000 \mathrm{~m})$ with change in ambient pressure and constant ambient temperature, engine speeds (800 rpm, $1000 \mathrm{rpm}, 1500 \mathrm{rpm}, 2000 \mathrm{rpm}$ and $2500 \mathrm{rpm}$ ) and pedal positions (1 bar BMEP, 25\%, 50\%, $75 \%$ and $100 \%$ ) has been carried out in order to identify main trends in engine control strategies and performance. The test campaign has been completed with NEDC tests at $150 \mathrm{~m}$, $1000 \mathrm{~m}, 2000 \mathrm{~m}$ and $3000 \mathrm{~m}$ in order to analyse the impact of altitude and performance based control strategies on engine emissions.

\section{Steady-state tests}

\section{Engine torque}

Results under steady-state conditions are plotted in contours integrated into torque vs. engine speed maps obtained at different altitudes. Figure 5 shows EGR valve position into the colored region of every altitude chart. Null values mean that the EGR valve is completely closed whilst $100 \%$ represents fully-open EGR valve. Black dots into the colored region define the operating points that has been tested.

Maximum engine torque is shown to decrease progressively as the altitude is increased. At $1000 \mathrm{~m}$ the maximum torque is still reached at $3000 \mathrm{rpm}$ despite the decrease of maximum torque for particular engine speeds. At $2000 \mathrm{~m}$ the maximum torque reduction is significant and affects the whole engine speed range defining the trend that finally leads to the fall found at $3000 \mathrm{~m}$. In this particular case, the engine has gone into a safe mode for pedal positions over $50 \%$ keeping torque constant from this value on. The safe mode aims for high surge margin but also avoids high compressor outlet temperature, which was found to slightly surpass $160{ }^{\circ} \mathrm{C}$, and high turbine inlet temperature, which reached values slightly over $800^{\circ} \mathrm{C}$.

This trend can be explained by two opposite effects. On one hand, boosting pressure gets decreased because of ambient pressure reduction, which should lead to a decrease of the engine air mass flow due to density drop. To offset this phenomenon, engine control closes the EGR valve as the operating altitude is increased. This valve gets completely closed from $2000 \mathrm{~m}$, as shown in Figure 5. EGR removal slightly increases fresh air mass flow for the same engine torque and speed conditions in comparison to the region in which EGR is open at $150 \mathrm{~m}$, as shown in Figure 6. However, the addition of both gas streams (EGR and fresh air mass flows) suffers a diminution as the operating altitude increases. Consequently, the in-cylinder trapped mass gets lowered at the intake valve closing and due to the limited charge dilution, the temperature increases significantly.

\section{VGT and boosting pressure}

With respect to the VGT behavior, there are two main strategies for VGT control depending on the engine operative area. On one side, the VGT position is within an openloop control at engine low load and low speed. In this area, the VGT position is set by ECU look-up tables, which are independent of the altitude. This operating region covers most of the points where the engine is running during the NEDC, except those at very high speed in the EUDC cycle. On the other side, the VGT position is set in the operating 
region at high engine load and speed in order to keep constant boosting pressure.

Nevertheless, there are not relevant differences in VGT position under steady-state operation as a function of the altitude, as shown in Figure 7. VGT position remains almost at the same position independently of the altitude. This means that boosting pressure cannot be not recovered, as evidenced in Figure 8. Comparing against $150 \mathrm{~m}$ in height, any other altitude presents boosting pressure reductions from 200 mbar to 300 mbar for the same engine torque and speed. It is due to the fact that the control strategy is prevailing the compressor safe operation and, therefore, keeps quite constant its pressure ratio instead of boosting pressure even at full-load, like in a pure open-loop control strategy.

\section{Compressor performance}

Figure 9 shows the full-load iso-lines, where EGR is closed, in the compressor map at different operating altitudes. All points with the same engine speed should collapse in the compressor map if the volumetric efficiency does not vary with altitude. This can be deduced from Equations 1 and 2:

$$
\begin{gathered}
\dot{m}=\eta_{v} \frac{n}{2} V_{D} \frac{p_{2}-\Delta p_{\text {cooler }}}{R T_{c o}} \\
\dot{m}^{*}=\left[\frac{V_{D}}{2} \frac{\sqrt{T_{10}}}{R T_{c o}}\left(1-\frac{\Delta p_{\text {cooler }}}{p_{2}}\right) \frac{p_{2}}{p_{20}}\right] \pi_{C} \eta_{v} n
\end{gathered}
$$

Equation 1 defines the engine mass flow as a function of the volumetric efficiency. Multiplying Equation 1 by $\sqrt{T_{10}} / p_{c o}$ Equation 2 is obtained. The expression between brackets in Equation 2 can be said not to change with altitude since $\left(1-\frac{\Delta p_{\text {cooler }}}{p_{2}}\right) \frac{p_{2}}{p_{20}}$ variation is lower than $1 \%$ and $T_{10}$ was controlled to be same in all tests. Therefore, only volumetric efficiency variation can explain the horizontal movement of the points with the altitude since compression ratio and engine speed were given by engine control or test definition. The volumetric efficiency variation can be explained by the exhaust gas back-flows during the openloop period of the engine cycle. Thus, the decrease of the boosting pressure as the altitude increases keeping constant the VGT position increases the exhaust gas back-flows. This happens especially at $3000 \mathrm{~m}$ resulting in the decrease of the full-load surge limit.

\section{Driving cycle tests}

The main objective of these tests is to analyse the engine performance and emissions during a NEDC. For the measurement of gaseous emissions, an exhaust gas analyser HORIBA 7100DEGR was used. HORIBA analysers specifications, measuring ranges and response time are adequate to meet the requirements established by the Standard ISO16183 for measuring the concentrations of the exhaust gas components under transient conditions (20). The sample line of the equipment is connected directly to the exhaust pipe and it is heated to maintain wall temperature around $190{ }^{\circ} \mathrm{C}$ and to avoid the condensation of hydrocarbons into the line. The line is extended from the exhaust pipe to the equipment units where the different analysers are located:

- The hydrocarbon analyser is a heated flame ionization detector (HFID) type, with detector, valves, pipe work, etc. heated so as to maintain gas temperature within $190 \pm 10^{\circ} \mathrm{C}$

- Nitrogen oxides are measured on a dry basis, by means of a heated chemiluminescent detector (HCLD) type with a $\mathrm{NO}_{2} / \mathrm{NO}$ converter. The sampling path is also maintained at a wall temperature of $190 \pm 10^{\circ} \mathrm{C}$ up to the converter.

- The carbon monoxide and dioxide are measured with an analyser of the non-dispersive infrared (NDIR) absorption type.

\section{MEDAS stability during dynamic tests}

Before to analyse the engine test data obtained under transient operating conditions, MEDAS stability in terms of pressure and temperature was checked. To achieve this purpose, NEDC at different altitudes were performed measuring the instantaneous pressure and temperature in MEDAS piping system. In particular, these magnitudes were measured in pipe (1b) in Figure 1, which corresponds to pipe A in Figure 4.

Figure 10 shows pressure and temperature deviation with respect to set point values demanded to MEDAS. As 
observed, maximum pressure peaks are below $20 \mathrm{mbar}$, what means that maximum deviation is about $150 \mathrm{~m}$. Most of the time pressure deviation is inside a margin of \pm 5 mbar, i.e. $40 \mathrm{~m}$, with respect to the set point pressure. Besides, the mean overall deviation is below $1.6 \operatorname{mbar}(13 \mathrm{~m})$ in all altitudes. With respect to temperature, its variation is below $1{ }^{\circ} \mathrm{C}$ and most of the time is below $0.5^{\circ} \mathrm{C}$, being the overall deviation below $0.2{ }^{\circ} \mathrm{C}$ in all altitudes. Due to the reduced margin of variation, intake engine conditions can be assumed to be constant. This high dynamic response of the altitude simulator is achievable because of the air mass flow through MEDAS was set to be constant during the tests. As previously explained, MEDAS works with more mass flow than the maximum required for the engine at any moment. The difference is the dilution mass flow across pipe (4a) in Figure 1. Thanks to this dilution system, the response against sudden change in engine operating point is very fast without affecting MEDAS operating conditions in the intake and exhaust paths.

According to these results, MEDAS simulated atmosphere can be concluded to reproduce different ambient conditions even in dynamic conditions. To further confirm this statement, Figure 11 compares compressor inlet pressure variation at $150 \mathrm{~m}$ over sea-level when the engine operates connected to MEDAS during the NEDC against when it operates at sea-level without MEDAS. It is evidenced that pressure in MEDAS connection is very stable and does not present any appreciable oscillation over the test. Besides, pressure at the compressor inlet shows the same variation with and without MEDAS. Both cases show similar pressure reduction when the engine sucks more air, which is caused by the increase in pressure drop in the intake filter and piping.

\section{Engine performance}

The tests campaign was performed in two different days according to data shown in Table 2. During the first day, three tests in a row were carried out simulating ambient conditions at $150 \mathrm{~m}$. The first cycle was run in cold conditions. At the end of this tests the engine had already completed the warmup being the following two tests performed consecutively. The second testing day was devoted to complete three tests following the same procedure but changing the operating altitude $(1000 \mathrm{~m}, 2000 \mathrm{~m}$ and $3000 \mathrm{~m})$. Therefore, each altitude test can be compared to a test at $150 \mathrm{~m}$ at the same engine wall temperature conditions: cold test at $1000 \mathrm{~m}$ is compared to cold test at $150 \mathrm{~m}$, whilst warm tests at $2000 \mathrm{~m}$ and $3000 \mathrm{~m}$ are compared to each warm test at $150 \mathrm{~m}$. Additionally, both $2^{\text {nd }}$ and $3^{\text {rd }}$ warm tests at $150 \mathrm{~m}$ are compared between them. This last comparison of the warm tests at $150 \mathrm{~m}$ is used to check repeatability of the testing campaign. Ambient temperature was constant in all tests, so that altitude variation means also pressure change.

Table 2. Dynamic tests campaign.

\begin{tabular}{lccc}
\hline \hline & Test 1 & Test 2 & Test 3 \\
\hline $\begin{array}{l}\text { Engine temperature } \\
\text { Altitude }\end{array}$ & Cold & Warm & Warm \\
$\quad$ & & \\
Day 1 & $150 \mathrm{~m}$ & $150 \mathrm{~m}$ & $150 \mathrm{~m}$ \\
Day 2 & $1000 \mathrm{~m}$ & $2000 \mathrm{~m}$ & $3000 \mathrm{~m}$ \\
\hline \hline
\end{tabular}

VGT control. VGT control is based on the insights described from steady-state tests but shows some differences due to dynamic corrections. As previously stated, VGT position is fixed while EGR valve is open whilst VGT controls boosting pressure in order to keep it constant from mediumhigh engine load. Additionally, under steady-state conditions it was shown that the boosting pressure target is reduced as altitude increases leading to pressure ratio-like control as a function of altitude. However, this behaviour is not found under transient operation. As shown in Figure 12(a), during the UDC phases boosting pressure and turbine inlet pressure decrease with altitude governed by ambient pressure reduction, with the only exception of accelerations. In this phases the turbine pressure ratio $\left(\pi_{T}\right)$ at high altitude is always over the value at $150 \mathrm{~m}$ increasing the power transferred to the compressor. This behaviour is much more marked during the EUDC phase. Dynamically, the VGT tends to be more and more closed as the altitude increases. This results in higher turbine expansion ratio despite of the lower turbine inlet pressure. Consequently, compressor pressure ratio $\left(\pi_{C}\right)$ increases, as shown in Figure 12(b). In spite of this increase in turbine and compressor pressure ratios, they are not big enough to compensate the decrease in ambient pressure. Dynamic corrections of the VGT and corresponding turbine inlet pressure peaks are not enough to recover boosting pressure target at sea-level so that this must be decreased with altitude increments. Boosting pressure just 
surpass $150 \mathrm{~m}$ values in case of $1000 \mathrm{~m}$ during the final EUDC acceleration.

Regarding the compressor operating conditions during NEDC, Figure 13 represents them on the compressor map at the four studied altitudes. It can be said that pressure ratio growing at EUDC, as shown in Figure 12(b), increases the risk of over-speed during driving cycles. Figure 12(b) also shows that surge risk is not high during NEDC and barely increases at UDC $\left(\pi_{C}<1.5\right)$ due to the higher pressure ratio as altitude increases.

Air mass flow. Fresh air mass flow increases with the altitude, as shown in Figure 14, where the deviation in accumulated mass has been represented according to Equation 3:

Variable deviation $_{\text {alt }}^{t}=100 \frac{\sum_{0}^{t} \text { Variable }_{\text {alt }}-\sum_{0}^{t} \text { Variable }_{150}}{\sum_{0}^{t} \text { Variable }_{150 \mathrm{~m}}}$

Measured total air mass in altitude conditions has always been higher than at $150 \mathrm{~m}$. The maximum fresh air mass is obtained at $1000 \mathrm{~m}$ above sea-level, decreasing at $2000 \mathrm{~m}$ and $3000 \mathrm{~m}$ because of the decrease in boosting pressure with the altitude.

The increase in fresh air mass flow can be explained by the different strategies in the VGT and EGR control. During UDC phase (zone A in Figure 14), fresh air mass flow is increased at $1000 \mathrm{~m}$ and $2000 \mathrm{~m}$ because EGR is progressively closed with altitude, in spite of the fact that average boosting pressure is lower because VGT is openloop controlled. At $3000 \mathrm{~m}$, fresh air decreases with respect to $2000 \mathrm{~m}$. It is due to several reasons. On one hand, at $2000 \mathrm{~m}$ EGR is already fully closed. Additionally boosting pressure is as expected much lower as altitude increases and exhaust gas back-flows become much higher. At the beginning of the EUDC (zone B in Figure 14), VGT is still open-loop controlled. However, EGR slightly opens at $150 \mathrm{~m}$ with respect to zone A whilst gets closer at $1000 \mathrm{~m}$. Consequently, the growing trend in fresh air mass increases with respect to zone A for all altitudes over $150 \mathrm{~m}$. Moreover, dynamic response of the VGT open-loop control are also more aggressive in zone B. Another important phenomena during operation in the VGT open-loop region (zones A and $\mathrm{B})$ is that boosting pressure and turbine inlet pressure are higher at $1000 \mathrm{~m}$ than at sea-level in some accelerations. Also a relevant increase is noticed at $2000 \mathrm{~m}$ and $3000 \mathrm{~m}$. This is caused by the dynamic corrections on the VGT open-loop control and increases fresh air mass flow in these regions, which increases further turbine inlet pressure and pumping losses.

In zone C, the VGT is controlling in closed-loop and provides at least the same boosting pressure for all the altitudes, as shown in Figure 12(a). EGR is just still open at $150 \mathrm{~m}$. This makes the fresh air mass flow increase even more with respect to low altitude conditions. Finally, in the first part of zone D air mass flow is constant for all the altitudes because EGR is closed for all the altitudes and boosting pressure is the same for all of them controlled by the VGT. In the second part of zone D air mass flow decreases with the altitude because VGT stops controlling (opens), causing the boosting pressure to decrease with altitude because the VGT does not provide energy and the EGR valve is completely closed even at $150 \mathrm{~m}$.

Fuel consumption. Figure 15 shows the deviation in accumulated injected fuel mass of every test with respect to $150 \mathrm{~m}$ (note that deviation in test at $150 \mathrm{~m}$ is due to comparison between two tests as repeatability check). Two different trends are identified and conditioned by VGT and EGR control strategies.

On one hand, the increase in fresh air mass flow and turbine inlet pressure during UDC leads to higher pumping losses. Note that at $1000 \mathrm{~m}$ the increment is higher than at the rest of the altitudes because the engine is colder, causing the VGT to be even closer. In addition, EGR is present in the combustion chamber still at $1000 \mathrm{~m}$. As a consequence, $1000 \mathrm{~m}$ case is characterised by lower combustion temperature and lower maximum in-cylinder pressure than $2000 \mathrm{~m}$ and $3000 \mathrm{~m}$ cases, at which the EGR valve was fully closed. Therefore, the indicated efficiency is lower at $1000 \mathrm{~m}$ than at $2000 \mathrm{~m}$ and $3000 \mathrm{~m}$. During the accelerations in the UDC, fuel consumption suffers peaks at high altitude. These are caused by the dynamic response of the VGT, which closes to follow the vehicle acceleration imposed by the driving cycle. 
Concerning the EUDC where the VGT is controlling in closed-loop, pumping losses increase is more significant due to higher turbine inlet pressure (Figure 12(a)). It results in fuel consumption increase very fast at $2000 \mathrm{~m}$ and $3000 \mathrm{~m}$. At $1000 \mathrm{~m}$, there is not any fuel increase during EUDC phase because ambient pressure is not too low and the increment of boosting pressure is mostly achieved by the closer position of the EGR valve with respect to $150 \mathrm{~m}$.

\section{Emissions}

Finally, the analysis of the emissions during NEDC at different altitudes is performed. Measurements has been done downstream of the DOC. All the accumulated emission deviations represented in Figure 16 are calculated according to Equation 3. NOx emissions are higher as altitude increases. The main reason for NOx emissions increase is the EGR valve closing. At $2000 \mathrm{~m}$ and $3000 \mathrm{~m}$ the EGR valve is fully closed during the whole NEDC, being NOx emissions very similar between them. This result is slightly different compared to data shown by Wang et al. (10), where NOx emissions decrease at $3200 \mathrm{~m}$ with respect to $2800 \mathrm{~m}$. However, results are similar to the one obtained by $\mathrm{Yu}$ et al. (21) where NOx emissions barely change at high altitude. These different NOx emissions trends can be strongly affected by particular EGR strategies in each tested engine and remarks the importance of an appropriate control strategy focused on emissions reduction at high altitude.

THC and CO emissions also show dramatic increase with altitude. DOC was not activated until late in the EUDC part of the NEDC, where Figure 16 shows that $\mathrm{CO}$ emission flattens but THC are still increasing. Their increase before catalyst activation at high altitude is partly explained by the prevalence of the jet-to-wall impingement, which is caused by the lower pressure in the combustion chamber during fuel injection (lower boosting pressure). CO and THC emissions are especially relevant in the accelerations taking place along the UDC phase, due to the increased exhaust gas back-flows when boosting pressure is low but turbine inlet pressure grows suddenly due to VGT closing.

As gaseous pollutants, soot emissions also increase with altitude. The cause is very similar to the increase of $\mathrm{CO}$, also with peaks at the highest altitude. At the last part of the
EUDC, soot emissions decreases at altitude. This is due to two reasons. On one hand, VGT controls boosting pressure, what balance jet-to-wall impingement at high altitude. In addition, EGR is fully closed at altitude but still open at sealevel, what also increases soot formation at sea-level with respect to altitude operation.

Regulated emissions are summarised in Figure 17, which shows emissions at the different tested altitudes in grams per kilometre distinguishing between UDC and EUDC phases of NEDC. All pollutant emissions increase as altitude does from two to three times the emitted mass at $150 \mathrm{~m}$ caused mainly by the EGR closing (high temperature in combustion chamber), VGT closing (exhaust back-flows) and lower boosting pressure (jet-to-wall impingement).

\section{Summary and conclusions}

In this paper, an altitude simulator has been presented as an efficient tool to analyse the performance and emissions dependence on altitude of internal combustion engines. In particular, the behaviour of a turbocharged Diesel engine has been analysed comparing four different altitudes from $150 \mathrm{~m}$ to $3000 \mathrm{~m}$. MEDAS has been proved to provide stable pressure and temperature conditions showing its operating range in terms of maximum mass flow as a function of altitude as well as its dynamic response.

With respect to the engine behaviour in altitude, steadystate tests show different trends than dynamic tests due to dynamic control corrections. The most relevant change observed under steady-state operation is the reduction of the maximum torque with altitude, specially reduced at $3000 \mathrm{~m}$ because the engine goes into a safe mode protecting the compressor from surge and turbine from too high temperature. As altitude increases, EGR valve is gradually closed, being completely closed from $2000 \mathrm{~m}$. This strategy makes EGR flow increase. With respect to VGT, it operates according to an open-loop control strategy inside the EGR operating region, but applying dynamic corrections in the accelerations during the dynamic tests and additional corrections during engine warm-up. Only during the EUDC, VGT clearly operates in closed loop in order keep boosting pressure constant for whatever the altitude. 
VGT dynamic actuations during EDC generate severe peaks of pressure in the exhaust manifold. Those pressure peaks in the exhaust plus a low boost pressure in the intake manifold increase engine pumping losses, reduce indicated efficiency and increase engine back-flows with a severe penalty in bsfc and emissions. According to emission results, control strategies should be moved from just performance and mechanical protection criteria to raw emissions abatement in order to be able to meet incoming pollutant standards requirements at altitude together with a proper selection and sizing of aftertreatment systems.

\section{References}

[1] Tutuianu M, Bonnel P, Ciuffo B, Haniu T, et al. Development of the World-wide harmonized Light duty Test Cycle (WLTC) and a possible pathway for its introduction in the European legislation. Transportation Research Part D: Transport and Environment 2015; 40:61-75.

[2] ISO 2533:1975. Standard Atmosphere.

[3] Hiroyasu H, Arai M, and Tabata M. Empirical equations for the Sauter Mean Diameter of a Diesel spray. SAE Technical Paper 890464, 1989.

[4] Kihm KD, Terracina DP, Payne SE and Caton JA. Synchronized droplet size measurements for coal-water slurry sprays generated from a high-pressure Diesel injection system. Journal of the Institute of Energy 1974; 67470:2-9.

[5] Zama Y, Ochiai W, Furuhata T and Arai M. Experimental study on spray angle and velocity distribution of diesel spray under high ambient pressure conditions. Atomization and Sprays 2011; 21(12):989-1007.

[6] Shen L and Shen Y. Combustion process of diesel engines at regions with different altitude. SAE Technical Paper, 950857, 1995.

[7] Dec JE. A conceptual model of DI diesel combustion based on laser sheet imaging. SAE Technical Paper 970873, 1997.

[8] Wu H, Nithyanandan K, Zhou N, Lee TH, Lee CF and Zhang C. Impacts of acetone on the spray combustion of AcetoneButanol-Ethanol (ABE)-Diesel blends under low ambient temperature. Fuel 2015; 142:109-116.

[9] Zhu Z, Zhang F, Li C, Wu T, Han K, Lv J, Li Y and Xiao $\mathrm{X}$. Genetic algorithm optimization applied to the fuel supply parameters of diesel engines working at plateau. Applied
Energy 2014; 157:789-797.

[10] Wang X, Yin H, Ge Y, Yu L, Xu Z, Yu C, Shi X and Liu H. On-vehicle emission measurement of a light-duty diesel van at various speeds at high altitude. Atmospheric Environment 2013; 81:263-269.

[11] Human DM, Ullman TL and Baines TM. Simulation of high altitude effects on heavy-duty Diesel emissions. SAE Technical Paper 900883, 1990

[12] Li X, Xu S, Xiong Y and Liu X. Effects of oxygenated fuel on diesel engine performance under the simulated condition of plateau area. Acta Petrolei Sinica (Petroleum Processing Section). 2016; 321:215-220.

[13] Zhu H, Bohac SV, Huang Z and Assanis DN. Emissions as functions of fuel oxygen and load from a premixed low-temperature combustion mode. International Journal of Engine Research 2014; 15(6):731-740.

[14] Shi X, Wang T and Ma C. Simulations of the diesel engine performance with a two-stage sequential turbocharging system at different altitudes. Proceedings of the Institution of Mechanical Engineers, Part D: Journal of Automobile Engineering 2014; 22814:1718-1726.

[15] Payri F, Desantes JM, Galindo J and Serrano JR. Unit for simulating the pressure and temperature conditions of the air drawn in by a reciprocating internal combustion engine. Patent ES2398095B1, EP2672248(A4), US9038578(B2), JP5788025(B2), CN103392121(B), Spain, 2011.

[16] Desantes JM, Galindo J, Payri F, Piqueras P and Serrano JR. Atmosphere conditioning device for testing of combustion engines, procedure and related use. Patent ES2485618(B1), WO2015110683(A1), Spain, 2014.

[17] Desantes JM, Galindo J, Payri F, Piqueras P, Serrano JR. Device for conditioning the atmosphere in alternative internal combustion engine tests, procedure and use of said device. Patent ES2544516(B1), WO2016116642(A1), Spain, 2016.

[18] Galindo J, Serrano JR, Piqueras P, and Gómez J. Description and performance analysis of a flow test rig to simulate altitude pressure variation for internal combustion engines testing. SAE International Journal of Engines 2014; 74:2014-012582.

[19] Serrano JR, Piqueras P, Angiolini E, Meano CM, de la Morena J. On cooler and mixing condensation phenomena in the longroute exhaust gas recirculation line. SAE Technical Paper 
2015-01-2521, 2015.

[20] ISO-16183:2002. Heavy duty engines - Measurement of gaseous emissions from raw exhaust gas and of particulate emissions using partial flow dilution systems under transient test conditions.

[21] Yu L, Ge Y, Tan J, He C, Wang X, Liu H, Zhao W, Guo J, Fu G, Feng $X$ and Wang X. Experimental investigation of the impact of biodiesel on the combustion and emission characteristics of a heavy duty diesel engine at various altitudes. Fuel 2014; 115:220-226.

\section{Nomenclature}

$\begin{array}{ll}\text { BGR } & \text { Burn Gas Ratio } \\ \text { BMEP } & \text { Brake Mean Effective Pressure } \\ \text { DOC } & \text { Diesel Oxidation Catalyst } \\ \text { ECU } & \text { Engine Control Unit } \\ \text { EGR } & \text { Exhaust Gas Recirculation } \\ \text { EUDC } & \text { Extra Urban Driving Cycle } \\ \text { ISA } & \text { International Standard Atmosphere } \\ \dot{m} & \text { Mass flow } \\ \dot{m} * & \text { Reduced mass flow } \\ \text { MEDAS } & \text { Mobile Efficient Dynamic Altitude Simulator } \\ \mathrm{n} & \text { Engine speed } \\ \text { NEDC } & \text { New European Driving Cycle } \\ \text { OP } & \text { Over-pressure } \\ \mathrm{p} & \text { Pressure } \\ \mathrm{R} & \text { Gas constant } \\ \mathrm{T} & \text { Temperature } \\ \text { UDC } & \text { Urban Driving Cycle } \\ V_{D} & \text { Cylinder displacement } \\ \text { VGT } & \text { Variable Geometry Turbine } \\ \text { WG } & \text { Waste-Gate } \\ \text { WLTC } & \text { Worldwide harmonized Light vehicles Test Cycle }\end{array}$

Greek letters

$\begin{array}{ll}\Delta & \text { Difference, increment } \\ \pi & \text { Pressure ratio } \\ \eta_{v} & \text { Volumetric efficiency } \\ \text { Subscripts } & \\ 0 & \\ 1 & \text { Stagnation conditions } \\ 2 & \text { Compressor inlet } \\ & \text { Compressor outlet }\end{array}$

3 Turbine inlet

4 Turbine outlet

co Cooler outlet

C Compressor

t Time

$\mathrm{T}$ Turbine 


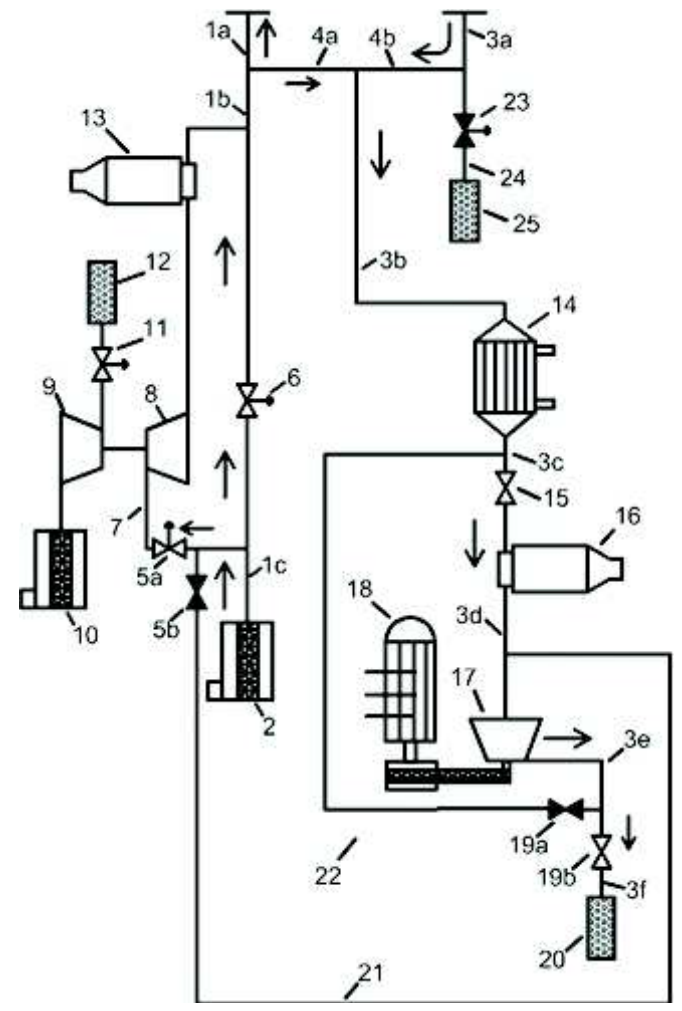

Figure 1. MEDAS layout in vacuum mode.

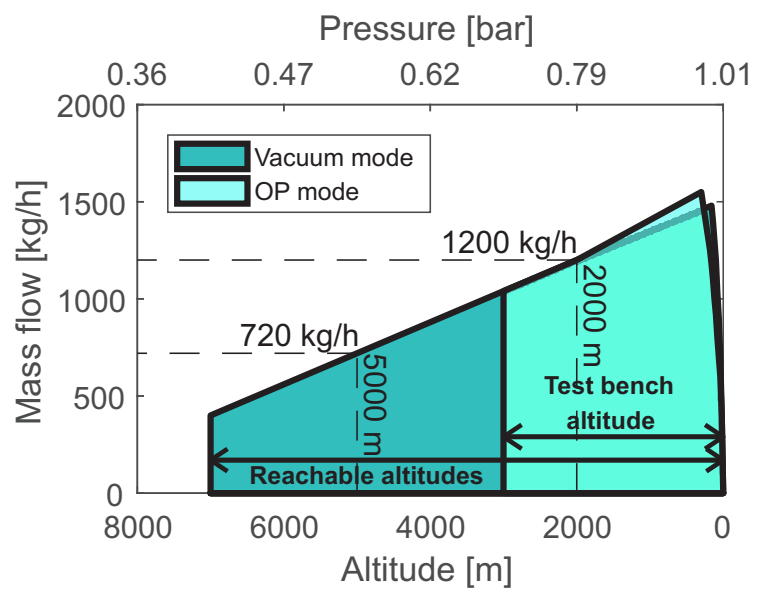

Figure 2. MEDAS mass flow and altitude operating range in a test bench placed at up $3000 \mathrm{~m}$ in altitude. 


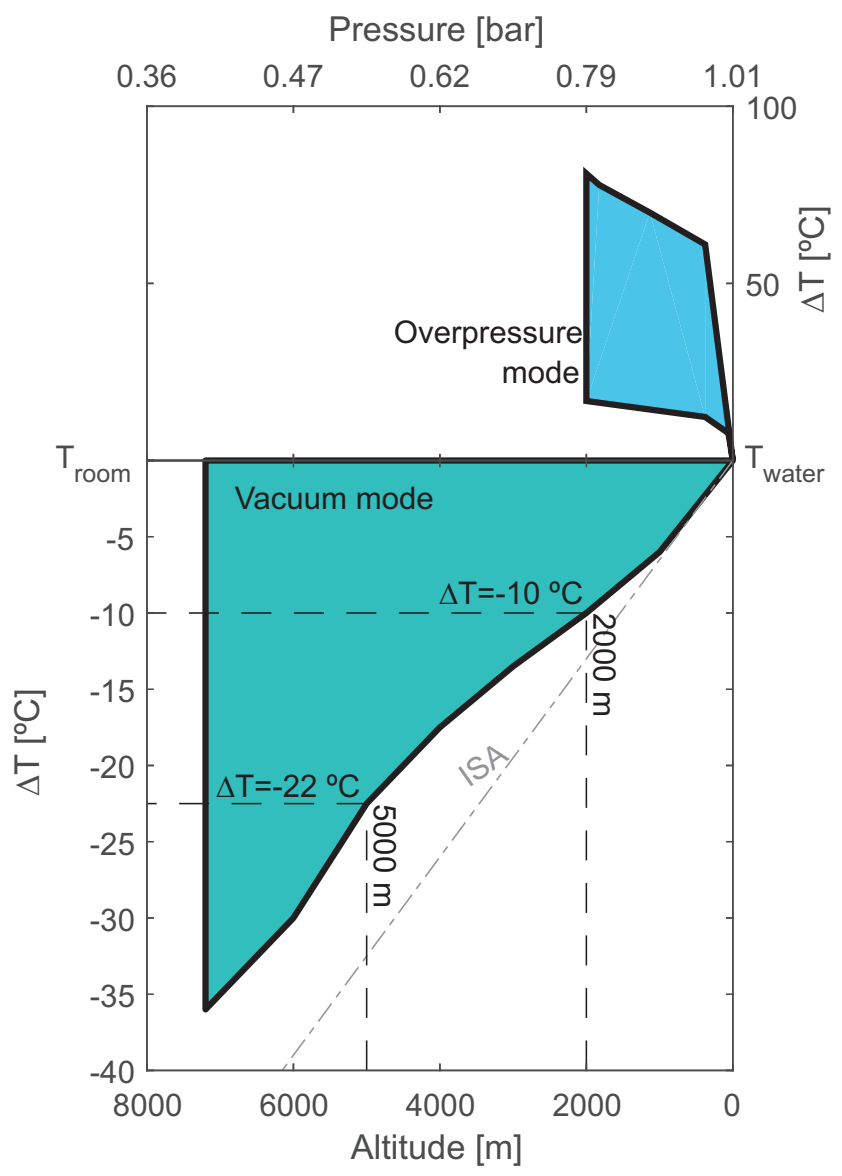

Figure 3. Temperature variation with respect to ambient conditions in vacuum and over-pressure modes. 

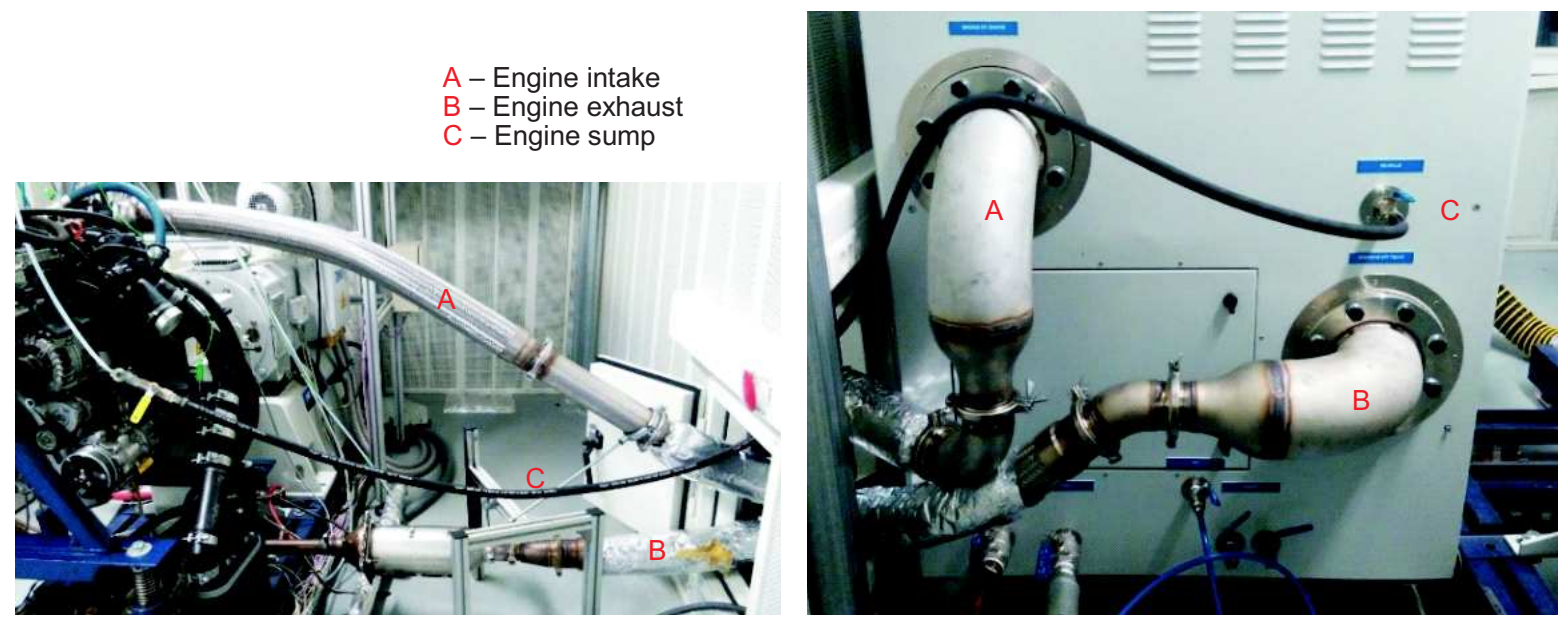

Figure 4. Engine (left) and MEDAS (right) connections.

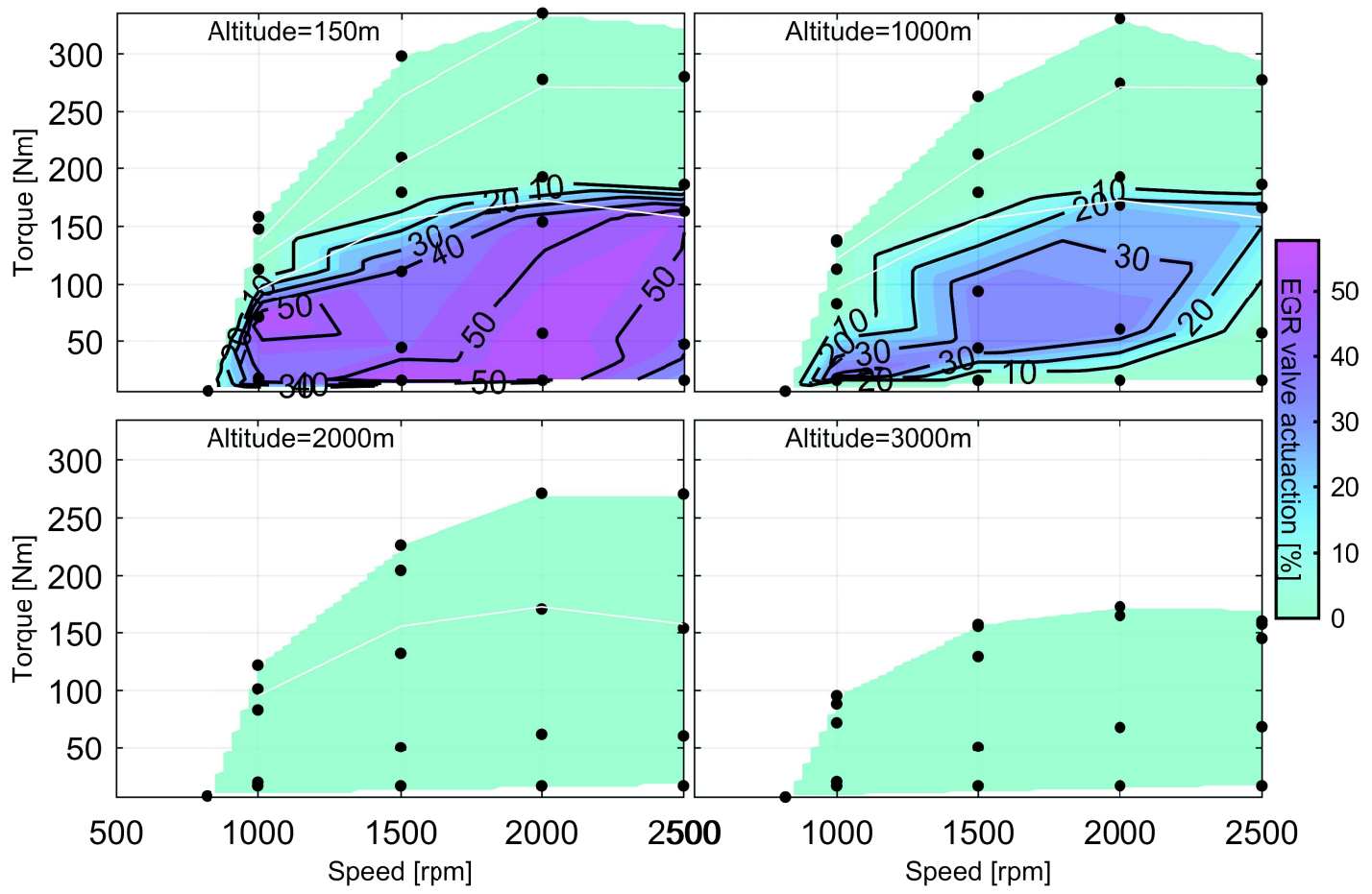

Figure 5. EGR valve position at different altitudes as a function of torque and engine speed. 


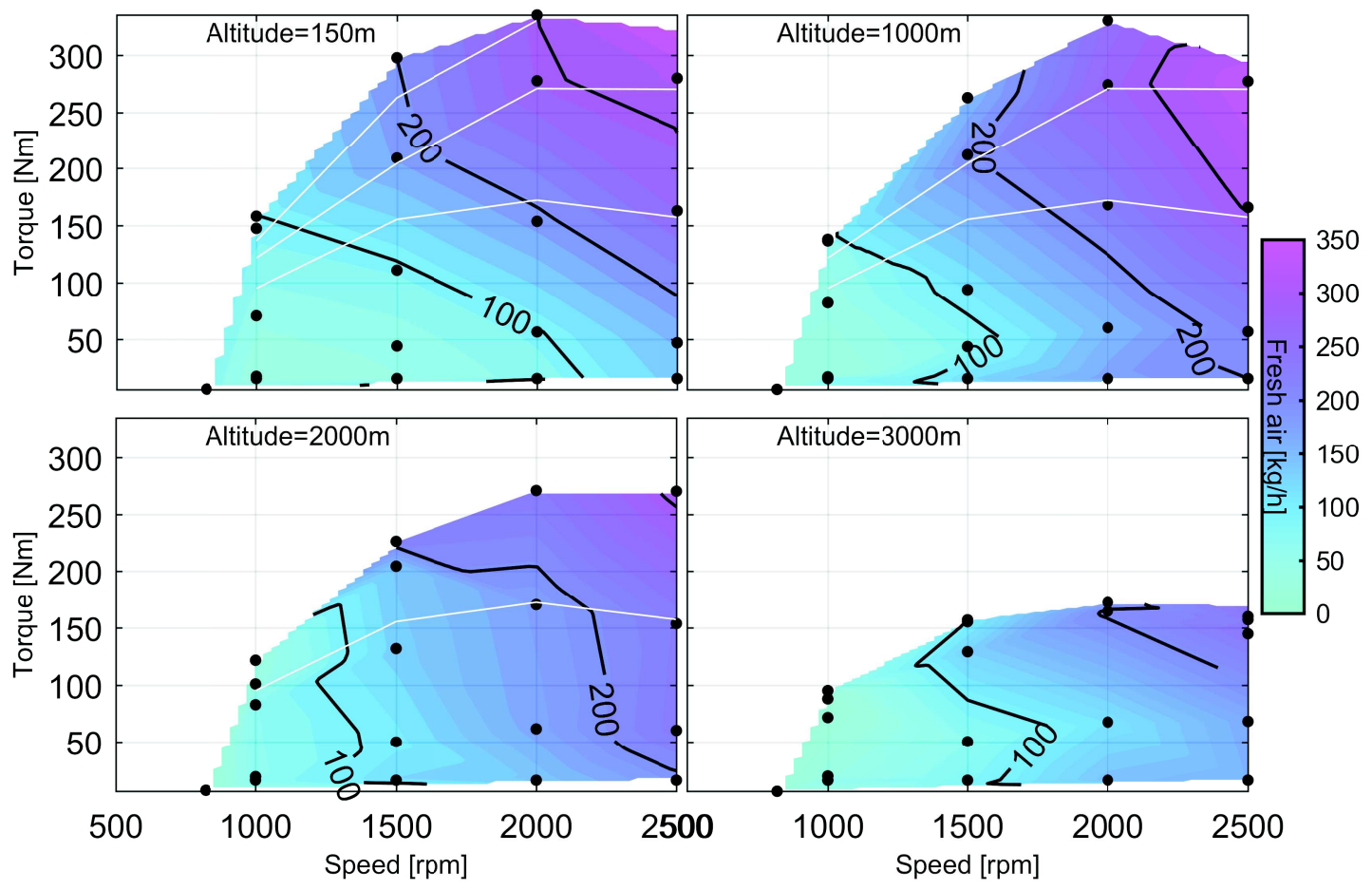

Figure 6. Fresh air mass flow at different altitude as a function of torque and speed.

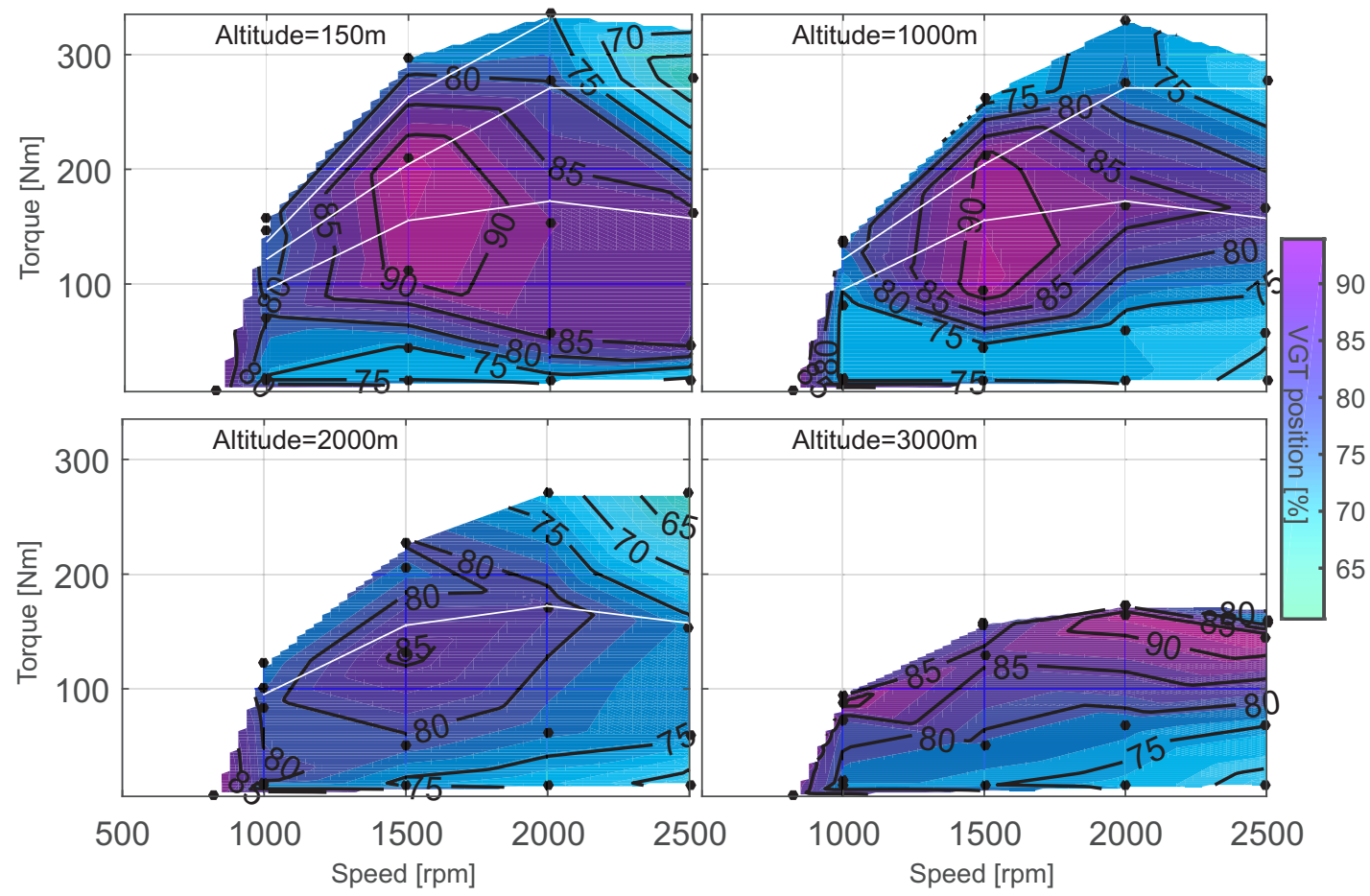

Figure 7. VGT position at different altitude as a function of torque and speed. 

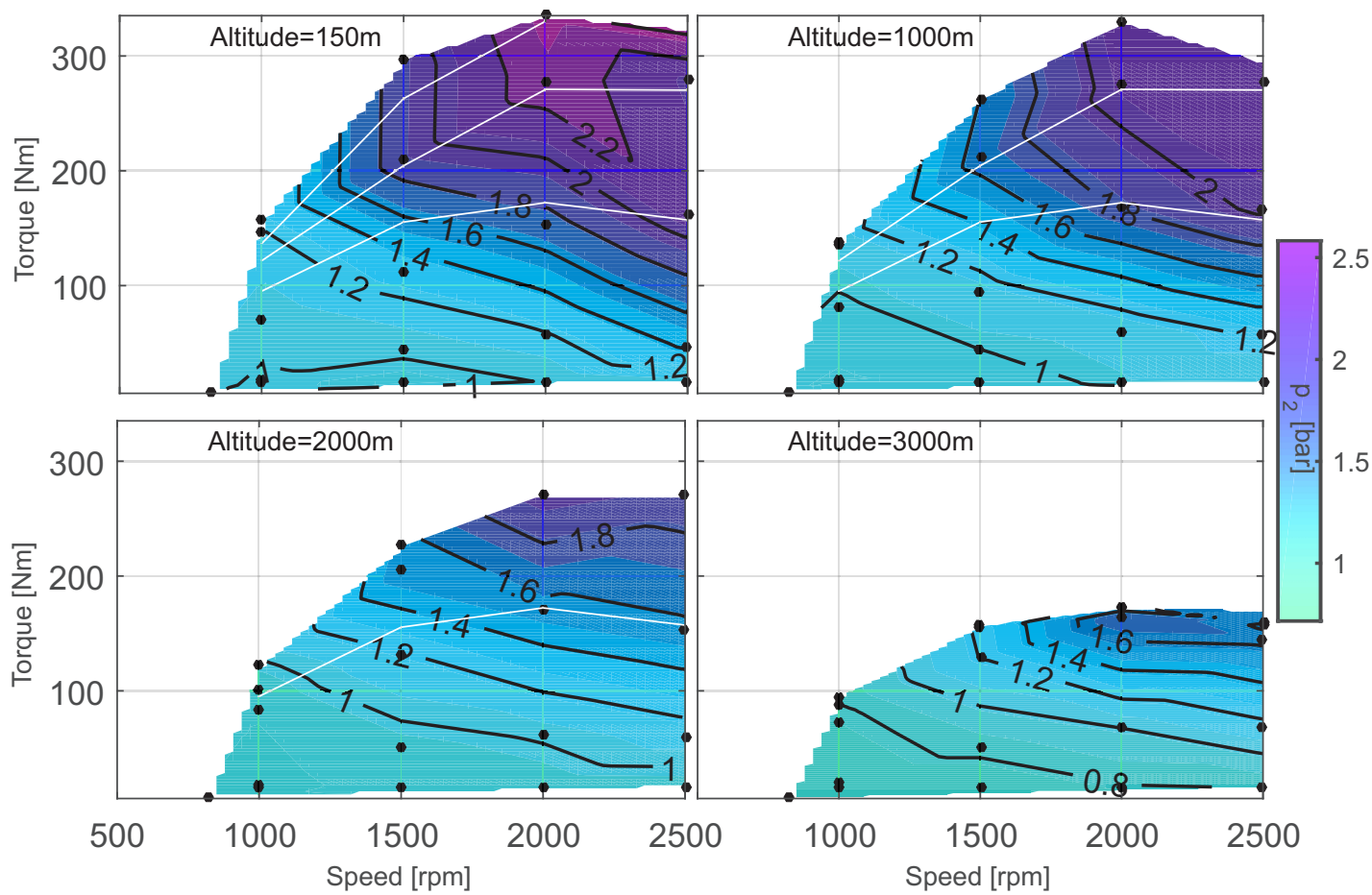

Figure 8. Boosting pressure at different altitude as a function of torque and speed.

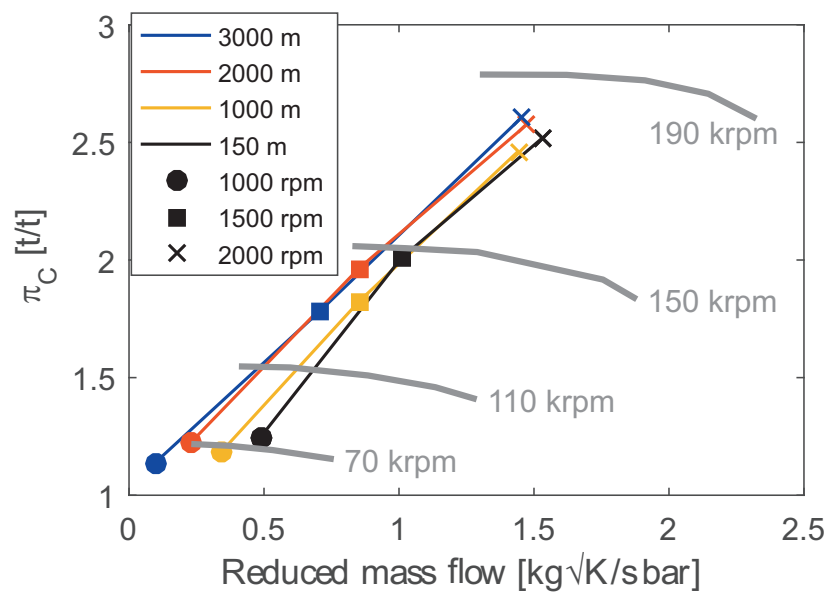

Figure 9. Compressor operation in full-load engine steady-state conditions at different altitude as a function of engine speed. 

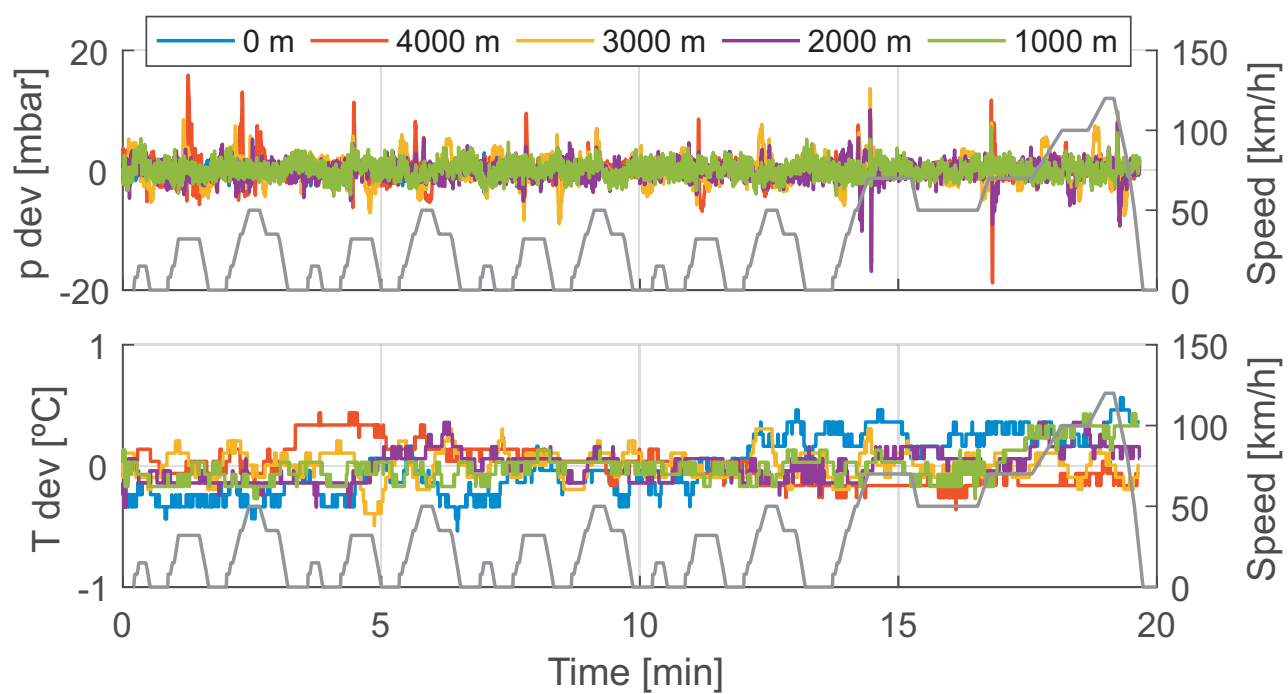

Figure 10. MEDAS dynamic response: pressure and temperature deviation with respect to set point during NEDC.

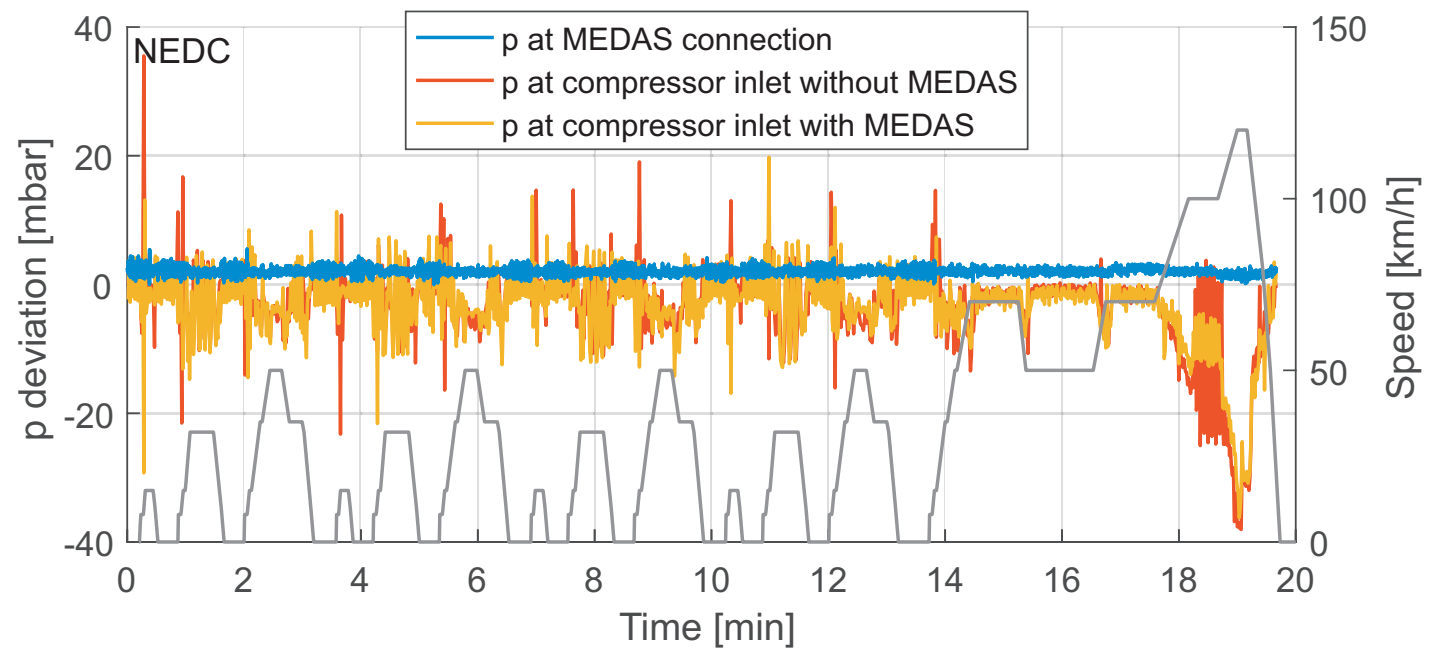

Figure 11. MEDAS dynamic response: comparison of pressure deviation at compressor inlet during NEDC. 


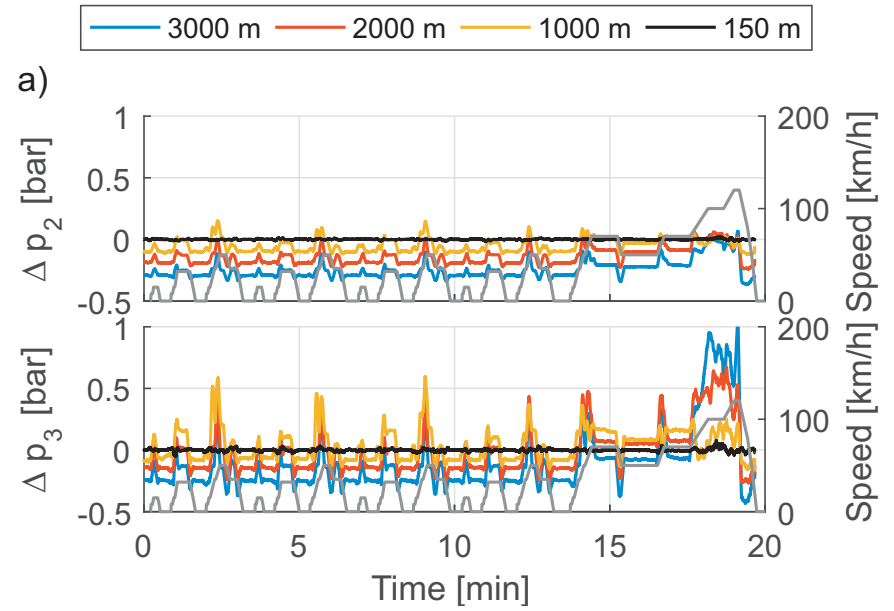

b)

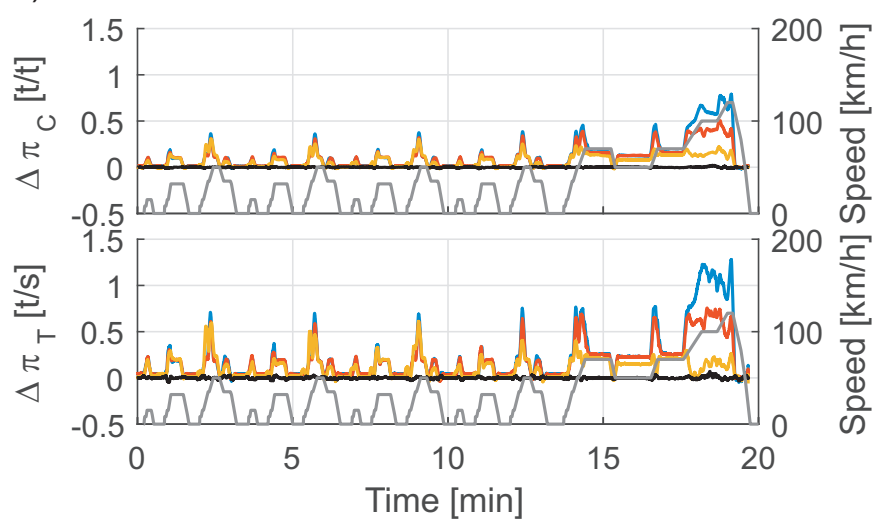

Figure 12. Instantaneous differences of variables at different altitudes with respect to $150 \mathrm{~m}$ during NEDC: (a) boosting pressure and turbine inlet temperature; (b) compression ratio and expansion ratio.

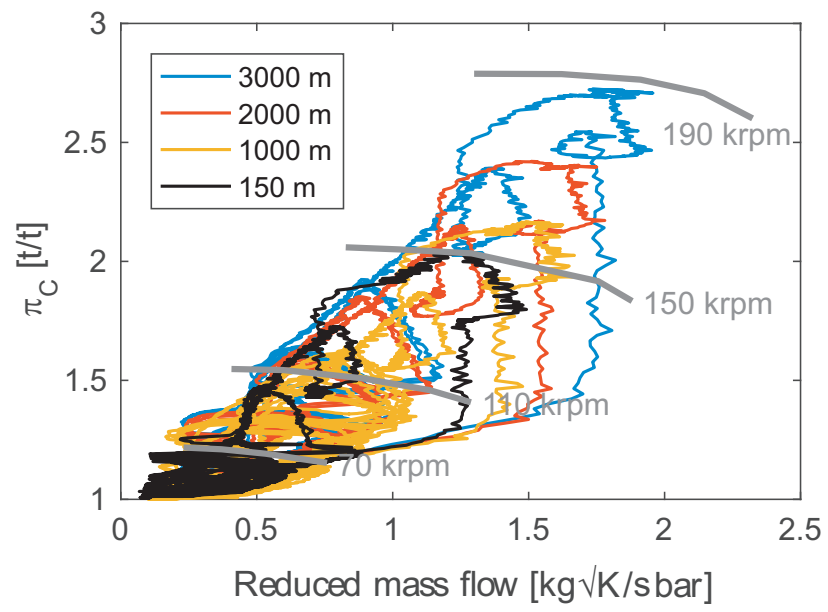

Figure 13. Compressor operating conditions during NEDC at different altitude as a function of engine speed. 


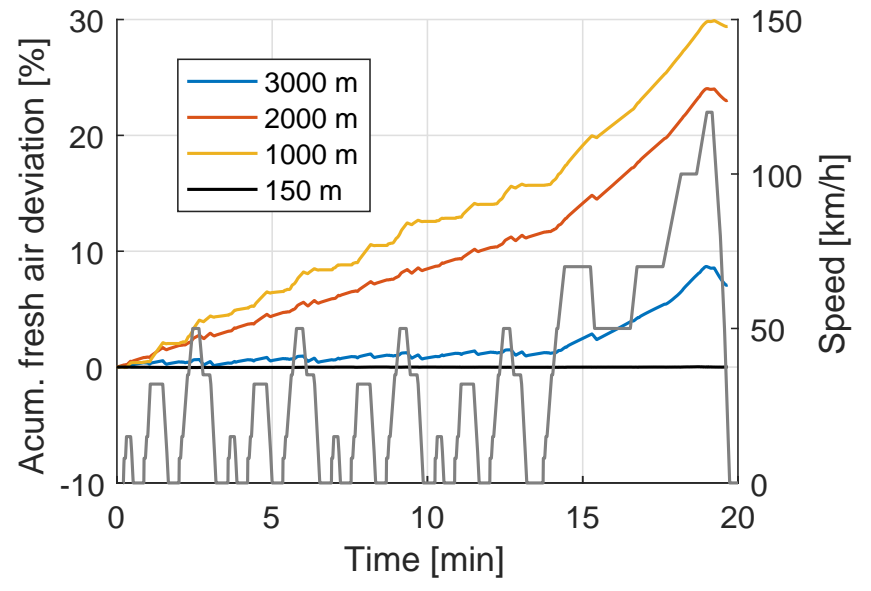

Figure 14. Accumulated deviation of fresh air mass during NEDC with respect to $150 \mathrm{~m}$ as a function of the operating altitude.

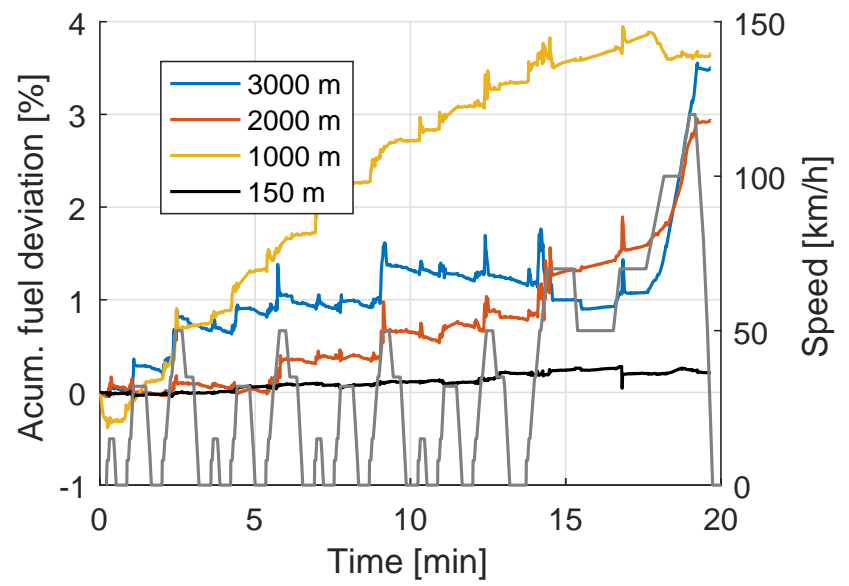

Figure 15. Accumulated deviation of fuel mass during NEDC with respect to $150 \mathrm{~m}$ as a function of the operating altitude. 

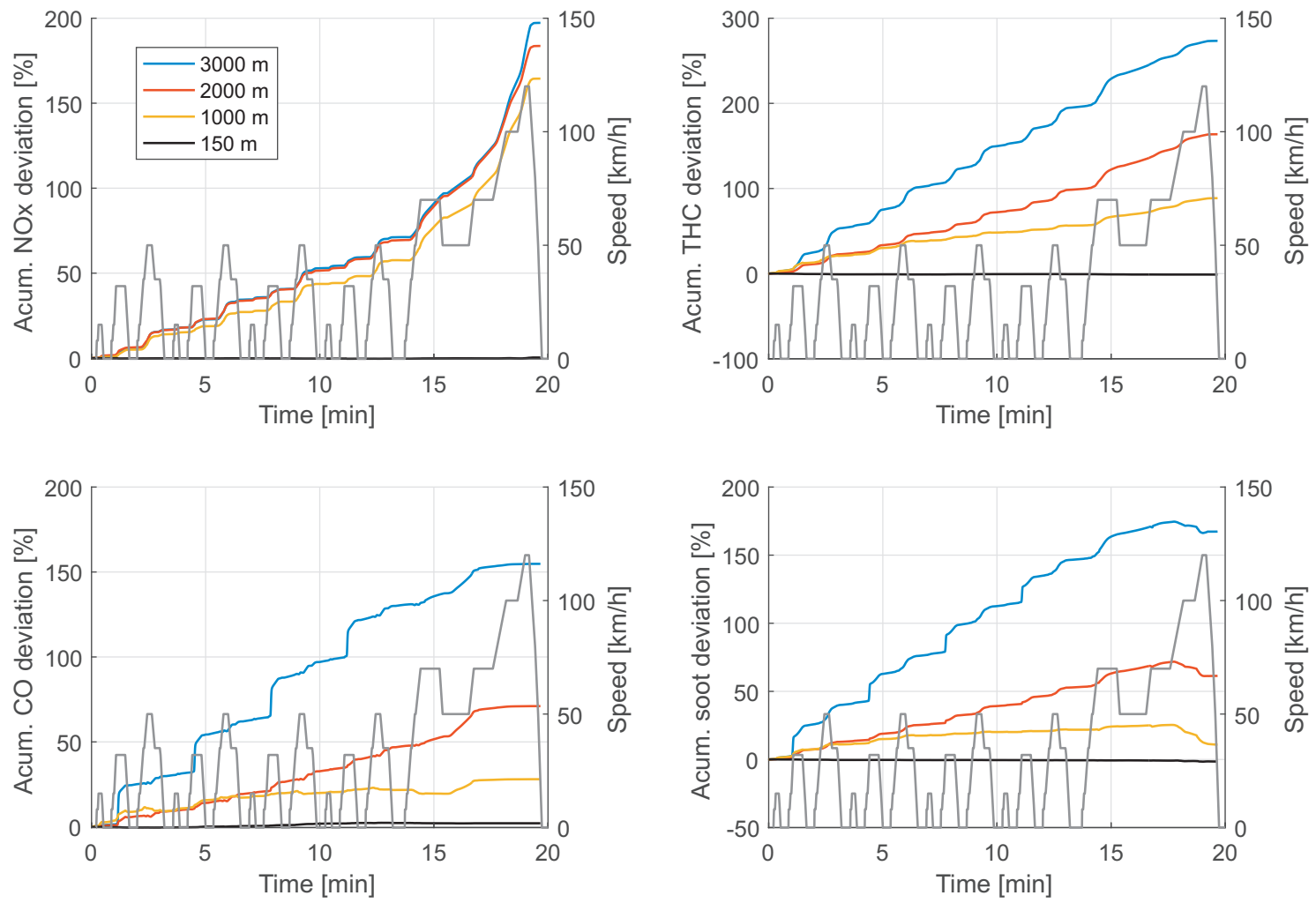

Figure 16. Accumulated deviation of regulated emissions during NEDC with respect to $150 \mathrm{~m}$ as a function of the operating altitude.
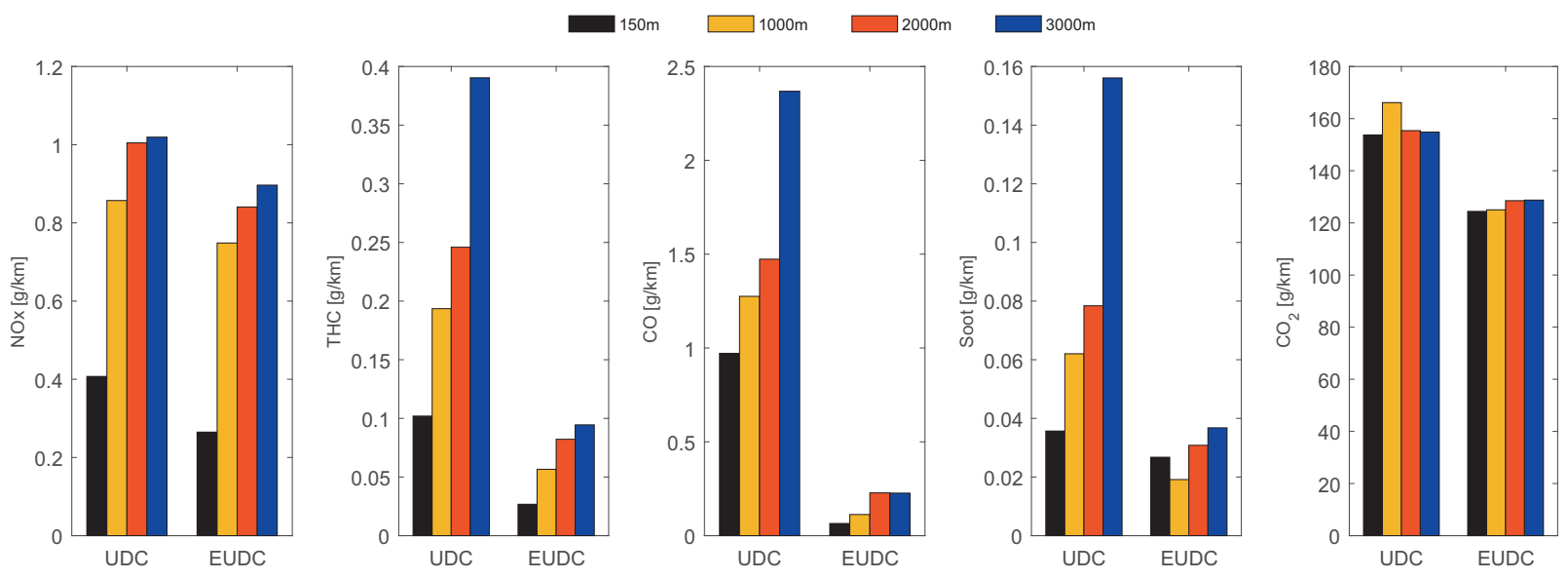

Figure 17. Regulated and $\mathrm{CO}_{2}$ emissions in UDC and EUDC phase of NEDC as a function of the operating altitude. 